\title{
The influence of customer-to-customer interactions on elderly consumers' satisfaction and social well-being
}

\author{
Authors: \\ Levent Altinaya, Haiyan Song, Melih Madanoglu, Xuan Lorna Wang
}

\begin{abstract}
This study highlights the valuable role the hospitality industry can play in addressing a societal problem by studying how social interactions between elderly consumers and other customers influence the satisfaction and social well-being of the former. The data were collected from 268 elderly consumers in local coffee shops in the United Kingdom using a self-administrated questionnaire. The findings reveal that elderly customers' interactions with other customers have a direct effect both on customer satisfaction and social well-being. They also show that social interactions with other customers have both direct and indirect effects on the social well-being of elderly customers. The study provides good evidence for how commercial hospitality settings can serve as a space for social exchange that helps to alleviate social isolation.
\end{abstract}

\section{Keywords:}

elderly consumers, social well-being, hospitality, social interaction with customers, customer-tocustomer interaction, customer satisfaction.

\section{Introduction}

The hospitality industry, in both its commercial and non-commercial forms, plays a central role in establishing and nurturing community life and well-being. Although the industry is frequently criticized for its promotion of unhealthy eating and drinking and for its contribution to public disorder, how it addresses social concerns is under-investigated (Lugosi, 2009). Acknowledging the role of hospitality social spaces, Dunbar (2016) investigated how "local community pubs" could enhance the social well-being of the local community, and found that social networking and interactions had dramatic effects on the health, well-being, and happiness of the community. He also recommended that pub owners work closely with their local communities to develop social spaces that could improve the well-being of those within them.

Limited or no social interaction with others negatively affects the well-being of individuals (Rook, 1984). This is considered one of the most serious societal issues among the elderly population in both the United Kingdom (U.K.) and European Union and has economic and sociocultural implications (Windle, Francis and Coomber, 2014). For example, an estimated 1 million older people 
in the U.K. have not spoken to another individual for periods of up to a month at a time (Jopling, 2015). Such social isolation leads to negative effects on physical and mental health, increased stress and mortality, poor sleep, and eventually increased use of health and social care services (Ayis, Gooberman-Hill and Ebrahim, 2003; Lauder, Mummery, Jones and Caperchione, 2006). The issues surrounding individual well-being and health status, along with the financial and broader community imperatives, have created the national and international policy consensus that support must be provided to mitigate social isolation and to help elderly people living with, or on the brink of, loneliness.

Research, although limited, has found that increased social contact through leisure activities such as tourism, shopping, having a drink in a bar, or going to the theatre help to increase the satisfaction and social well-being and reduce the social isolation of older people (Toepoel, 2013; Breen, 2009; Pettigrew, 2007; Kim, Kang and Kim 2005; Neal, Uysal and Sirgy, 2007; Uysal, Sirgy, Eunju and Kim, 2016). Together, these studies suggest that the positive experiences of older consumers do not stem from consumption per se, but from the enjoyment and social connectedness associated with their involvement and participation in the consumption process. Such engagement facilitates social connectedness and is thus a critical bridge for maintaining a desired level of social well-being.

Marketing and retailing researchers have investigated the relationship between social interaction and customer satisfaction. The results of these studies emphasize the importance of interactions between employees and customers (Choi and Kim, 2013) and customer-to-customer interactions (CCls) to customer satisfaction (Srivastava and Kaul, 2014; Yo et al., 2012). However, the social outcomes of these interactions, such as their influence on the well-being of customers, have not been investigated. Tourism researchers including Wei et al. (2017), Huang and Hsu (2010), and $\mathrm{Wu}$ (2007) have also found that CCls influence both experience and customer satisfaction. However, these studies have not investigated how these interactions affect the well-being of customers, particularly the well-being of elderly customers in hospitality settings, including cafés and restaurants. The role of hospitality settings in helping to address a social problem is still awaiting empirical attention.

This study sought to explore how CCls influenced satisfaction and how this in turn enhanced the social well-being of older people by conducting structured interviews with people in the U.K. aged 60 or above who visited a coffee shop more than once a year. The study empirically tested the relationship between social well-being, CCls, and customer satisfaction. The findings demonstrate the importance of older people's interactions with other customers in enhancing their social wellbeing.

In addition, the study acknowledged that different types of interactions could occur among elderly customers and with other customers. Therefore, hospitality organizations must manage different types of interactions and design appropriate strategies to make the most of the potential effects of these interactions on satisfaction and social well-being while mitigating their possible consequences. Both employees and the "most experienced customers" can be trained to assist with elderly customers to enhance their satisfaction and social well-being. 


\section{Theoretical Foundation}

\subsection{Social Well-being}

Happiness, life satisfaction, and quality of life (QOL) are popular terms that are analogous to well-being and are often used interchangeably in the academic literature (Eger and Maridal, 2015). Well-being is also related to positive emotions resulting from interactions with others (Lamers, Westerhof, Bohlmeijer, Klooster and Keyes, 2011; Cheng, Lee and Chow, 2010).

QOL is the degree of satisfaction or dissatisfaction a person feels about various aspects of life (Abrams, 1973). It is the provision of the "necessary conditions for happiness and satisfaction" (McCall, 1975). Shin and Johnson (1978:475) defined QOL as "the possession of resources necessary to the satisfaction of individual needs, wants and desires, participation in activities enabling personal development and self-actualisation and satisfactory comparison between oneself and others." It is closely related to the concept of well-being, which is defined as "peoples' positive valuation of their lives, includes positive emotion, engagement, satisfaction and meaning" (Diener and Seligman, 2004:1).

Social well-being can be considered a dimension of QOL (Prince-Paul, 2008), and social psychologists apply it to address the social challenges of a well-lived life. It is defined as "the appraisal of one's circumstances and functioning in society" (Keyes, 1998:122). Subjective well-being refers to one's own evaluation of satisfaction with one's private life, but social psychologists argue that studies of well-being should acknowledge the division of life into private and public tasks (Keyes, 1998). The concept of "self" can be regarded as both a public process and a private product (Mead, 1934). For instance, positive psychology at the subjective level is "about valued subjective experiences" that include well-being and satisfaction (Seligman and Csikszentmihalyi, 2000:5). A well-known study in this field suggested that "very happy people were highly social, had stronger romantic and other social relationships than less happy group"(Diener and Seligman, 2002:81). The development of self-determination theory, "an empirically based theory of human motivation, development and wellness," has also drawn attention to the social self and social conditions that may enhance or diminish different types of motivation, such as controlled motivation and demotivation as predictors of performance, relational, and well-being outcomes (Deci and Ryan, 2008:182). Understanding an individual's social well-being from a social science perspective is thus important (Larson, 1993).

The social model of well-being developed by Keyes (1998) reflects positive social health and aims to address the social nature of life and the challenges that can affect any assessment of QOL. According to Dunbar (2016), social well-being that includes good relationships with others on a oneto-one, small group, or family level can have profound effects on mental health. A connected person is viewed as a supported individual in a community who is likely to be included and has a sense of belonging in society. For older customers, particularly those who live in a cosmopolitan environment such as the U.K., the ability to connect and have positive interactions with other customers from diverse cultural backgrounds within the local community can both expand their social networks and enhance their social well-being (Dunbar, 2016). 


\subsection{Customer-to-Customer Interaction}

Interactions between customers and their influence on customer satisfaction was identified as early as the 1970s (Woodside and Sims, 1976). Lehtinen and Lehtinen (1982) considered an interaction as the interface between a customer and a service provider. Bitner (1992:61) also acknowledged the critical importance of the social dimension of interactions in the servicescape framework, stating that the "servicescape influences the nature and quality of customer and employee interactions, most directly in interpersonal services." When assessing interaction quality, some scholars have suggested that customers assess service staff based on their knowledge, attitude, ability, and empathy (Backstrom and Johansson, 2006), while others have considered interaction quality as customers' perception of the manner in which a service is delivered during a service encounter (Gronroos, 1982, 1984; Lemke, Clark and Wilsom, 2011) and the interactions with service providers during service delivery (Brady and Cronin, 2001; Gronroos, 1982, 1984). Interpersonal interactions have been found to not only influence customer perceptions of service quality (Bitner, Booms and Mohr, 1994; Surprenant and Solomon, 1987), but also directly affect customer satisfaction (Gerrard and Cunningham, 2001; Jamel and Naser, 2002).

In many service settings, customers interact with other customers during service delivery or co-creation, such as by informing each other of the service instructions or assisting with the provision of the service. In addition to interactions with employees, both customer participation and $\mathrm{CCls}$ can influence customer experience and satisfaction (Moura and Amorim, 2017). Moura and Amorim (2017) developed a typology of $\mathrm{CCl}$ and its implications for excellence in service provision. This typology introduced four quadrants of service delivery: casual, functional, staged, and deliberate $\mathrm{CCls}$. In the case of casual $\mathrm{CCls}$, the interactions result from the inner characteristics of the service delivery system. Functional $\mathrm{CCls}$ evolve when service providers become aware of the gains that may be built from CCls. Staged $\mathrm{CCls}$ involve the positioning of services for which $\mathrm{CCls}$ are important and expected. Deliberate CCls involve the creation of service settings where both provider and customers are oriented to engage in CCls. Management of these interactions in service settings is crucial for better customer experience and satisfaction.

Studies have also demonstrated the interface between CCls, experience, and satisfaction. Yoo et al. (2012) investigated the effects of positive CCls between Korean hospital patients. Ekpo et al. (2015) also found that CCls affected both experience and satisfaction. In a study of older shopper behavior in a retail environment, Tomazelli et al. (2017) found that CCls that were related to the environmental elements of supermarkets tended to influence the shopping experiences of older shoppers, which had an impact on their satisfaction. Responding to a research gap between customer experience quality and $\mathrm{CCl}$ quality in mass service settings, Kim and Choi (2016) found that perceptions of friend interaction and audience interaction quality significantly influenced customers' experience quality in mass service settings. These studies made important contributions to knowledge by highlighting the importance of $\mathrm{CCls}$ to satisfaction. They also emphasized the importance of $\mathrm{CCls}$ to enrich customer experiences in hospital, health care, retail, and other mass service settings. However, these studies did not consider how these interactions took shape in hospitality-intense service environments such as restaurants and hotels or how they influenced customer satisfaction. More importantly, these studies did not consider the "social outcomes" of CCls, such as customers' well-being. 
Although limited in number, studies have been conducted in intense $\mathrm{CCl}$ hospitality settings such as cruise ships, conferences, and travel agencies. These studies have collectively highlighted the importance of CCls for better customer experience and satisfaction (Huang and Hsu, 2010; Wei et al., 2017; Wu, 2007; Yin and Poon, 2016). Huang and Hsu (2010) examined the interactions between tourists on cruise vacations and their impact on the cruise experience and vacation satisfaction. Yin and Poon (2016) examined the impact of other group members on the travel experiences of Chinese tourists participating in domestic package tours. This study identified the major categories of other customers' characteristics or behaviors that could positively or negatively influence the travel experiences of group package tourists. Wu (2007) investigated the impact of CCls and customer homogeneity on customer satisfaction in tourism services. These studies made important contributions to knowledge by offering new insights into the relationship between $\mathrm{CCls}$, experience, and satisfaction. However, they neglected the social outcomes of these interactions, such as their importance for customers' well-being and QOL, thus triggering a call for research in this area (Song, Altinay, Wang and Sun, 2018).

\subsection{Customer Satisfaction}

Customer satisfaction is a central concept in hospitality research (Srivastava and Kaul, 2014). Researchers have emphasized different dimensions of customer satisfaction in their studies. The process definition of customer satisfaction emphasizes the "expectancy disconfirmation paradigm" (Oliver and De Sarbo, 1988; Tse and Wilton, 1988; Yi, 1990), while other researchers have highlighted the "outcome" definition, emphasizing satisfaction as a state of fulfillment connected to reinforcement and arousal (Srivastava and Kaul, 2014). According to Srivastava and Kaul (2014), process definitions enable researchers to evaluate satisfaction by analyzing the service interactions and assessment of service experiences that involve consumption periods. This is particularly evident in hospitality and leisure organizations, which increasingly offer experiences in which the service providers can structure the environment and interactions to facilitate guests' experiences (Duerden, Ward and Freeman, 2015; Ellis, Freeman, Jamal and Jiang, 2017). Such developments should help companies to evaluate guest satisfaction more comprehensively, in a more structured manner, and at different stages of the consumption journey. Satisfaction is thus formed based on a single service encounter and on a number of service experiences. Oliver (2006), however, defined satisfaction as the fulfillment of consumers' consumption goals, and stated that it could only be described as a consumer's consumption experience.

In their investigation of the effect of both convenience and social interactions on customer satisfaction, Srivastava and Kaul (2014) identified two approaches to studying customer satisfaction: transaction-specific and cumulative or overall satisfaction. The transaction-specific approach defines customer satisfaction as an emotional response to the most recent transactional experience with the service provider (Oliver, 1993). Overall satisfaction refers to customers' overall and cumulative impression of the service provider's service, production, and product delivery performance. In hospitality outlets where both services and tangible hospitality products such as coffee, tea, and cakes are consumed, it is important to study both transaction-specific and cumulative satisfaction. As Esbjerg et al. (2012) and Oliver (1997) stated, in outlets where a critical aspect of satisfaction is the retail experience, satisfaction involves a post-consumption evaluation that captures both transaction and cumulative satisfaction measures. 


\subsection{Hypotheses Development}

\subsubsection{Customer-to-Customer Interaction and Social Well-Being}

$\mathrm{CCls}$ contribute to social connectedness and thus reinforce the sense of belonging and happiness in elderly customers (Kim et al., 2015; Uysal et al., 2016) or vulnerable groups such as health care patients (McColl-Kennedy, Danaher, Gallan, Orsingher, Lervik-Olsen and Verma, 2017). Helliwell and Putnam (2005) stated that social connectedness had a positive effect on subjective well-being. Palys and Little (1983) noted that a supportive social network was an essential influence on a person's life satisfaction. Studies have suggested that social connectedness and interactions with others affect the physical and psychological health of the elderly (Netuveli et al., 2005; Zaninotto et al., 2009). A lack of social connectedness may lead to loneliness and social problems (Lee et al., 2002). Levasseur et al. (2004) proposed that the more satisfied older people were with their social networks, the greater the influence on their QOL. However, Stalker (2008) and OrsegaSmith et al. (2007) cautioned that the characteristics of social engagement among the elderly had to be carefully understood so that patterns of social behavior and network characteristics that improved well-being later in life could be analyzed. Similarly, McColl-Kennedy et al. (2017) found that in the health care sector, understanding and managing patients' emotions during their interactions with other patients could also affect the patients' satisfaction and well-being.

Based on individual interviews, Pettigrew (2007) found that the consumption behavior and activities that facilitated social interaction could improve older people's perceived QOL. Places such as second-hand clothing stores, restaurants, and coffee shops can satisfy older consumers' companionship and emotional needs, as many of them enjoy conversation and entertainment in social settings, particularly if they perceive the establishment as a place for socializing and enjoying themselves (Pettigrew, 2007). The quality of social interaction is more important in enhancing the social well-being of older adults than the quantity, as not all interactions are supportive (Pinquart and Sörensen, 2001). Good quality contacts make the elderly feel confident, loved, and understood (Kim et al., 2003). Given these arguments, the following hypothesis is proposed.

H1: Social interactions with other customers have a positive influence on the social wellbeing of elderly customers.

\subsubsection{Customer-to-Customer Interaction and Satisfaction}

The link between CCls and satisfaction is a subject of increasing interest among services marketing and retailing researchers (Choi and Kim, 2013; McColl-Kennedy et al., 2015; Kim and Choi, 2016). Early studies suggested that a positive interaction had a positive effect on satisfaction (Aller and Van Ess Coeling, 1995; Mattiasson and Andersson, 1997; Patterson, 1997; Bitzen, 1998). Choi and Kim (2013) found that the perceived quality of peer interactions between customers contributed greatly to customer satisfaction. They concluded that $\mathrm{CCl}$ quality was essential to customer satisfaction. Similarly, Sacco and Ismail's (2014) research showed that face-to-face interactions and communication between customers led to satisfaction and encouraged them to engage in further interactions in the future. Yoo et al. (2012) also found that CCls reinforced role perceptions, participation, perceived service quality, and satisfaction among patients in a Korean hospital. Tomazelli et al. (2017) found that CCls in the shopping setting influenced the shopping experience of older shoppers, which affected their satisfaction. 
In the field of hospitality management, few studies have investigated the importance of CCls to customer satisfaction. Studies have investigated the influence of $\mathrm{CCls}$ on satisfaction on cruise ships, at conferences, and in travel agencies. Huang and Hsu (2010) found that the quality of $\mathrm{CCls}$ between cruise tourists had direct positive effects on the cruise experience and indirect effects on vacation satisfaction. Wei et al. (2017) found that conference attendees' experience and satisfaction were driven by their engagement in CCls. Wu's (2007) study of CCls during different incidents in travel agencies found that "protocol and sociable incident" had a significantly positive effect on the "evaluation of fellow customers." However, "malcontent incidents" had a significantly negative effect on customer satisfaction, "marital homogeneity" had a positive influence on the "evaluation of fellow customers" and "evaluation of fellow customers" had a positive influence on customer satisfaction.

Studies conducted in the health and elderly care contexts have also demonstrated that interactions between the elderly have a positive influence on their satisfaction. Bergland and Kirkevold (2008) revealed that residents' experiences and interpersonal relationships with peer residents contributed to their satisfaction with homecare services. Gutheil (1991) identified talking as the most popular form of interaction between peers in institutional care settings, through which residents could experience a mutual and caring social relationship and receive satisfactory homecare support. In addition, Carpentier (2015) and Yeung et al. (2013) discovered that residents with positive peer support were more motivated in their medical experiences, such as participation in treatment and rehabilitation programs. Given these outcomes, we make the following hypothesis.

H2. Elderly customers' social interactions with other customers have a positive influence on their satisfaction with coffee shops' products and services.

\subsubsection{Satisfaction and Social Well-Being}

Hospitality and tourism research interest in well-being has recently increased (e.g., Edgar, Geare, Saunders, Beacker and Faanunu, 2017; Zhou, Yu, Wu, Wall and Pearce, 2018; Lugosi et al., 2016). Research has demonstrated that leisure and tourism activities, such as traveling with friends and family members, walking for pleasure, camping, making art, using the Internet, and reading sessions in coffee shops, contribute to well-being (Uysal et al., 2016; Kim et al., 2015). Uysal et al. (2016) contributed to the ongoing debate by calling for more research into how leisure and tourism activities enhance the well-being of individuals. Researchers such as Sirgy (2012), Grzeskowiak et al. (2016), and Kim et al. (2015) have proposed that structural leisure (i.e., leisure-type activities and time spent working outside) and subjective leisure (i.e., perceived participation in leisure activities) contribute to subjective well-being through satisfaction with leisure life, which in turn contributes to overall life satisfaction. Similarly, the meta-analytic study conducted by Kuykendall et al. (2015) demonstrated that leisure engagement influenced subjective well-being via satisfaction with leisure life.

The benefits of leisure activity and engagement for well-being have also attracted much attention from researchers in the field of positive psychology in recent years. In particular, Linkins et al. (2015), White and Waters (2015), and Quinlan et al. (2015) identified different positive 
psychology interventions to alleviate psychological stress and promote well-being in individuals and communities.

Linkins et al. (2015) argued that a positive psychology-based approach sought to help individuals identify and engage their personal character strengths, thereby promoting well-being. White and Waters (2015) described five character strength initiatives. Four of the strength initiatives were integrated into existing school experiences including the English curriculum, school sports, student leadership, and counseling. The fifth initiative involved a brand new program. The authors described these five initiatives and then explained how students at the school could experience them in a more holistic and integrated way. Quinlan et al. (2015) argued that school-based strength interventions could influence individual perceptions of class climate, engagement, and student relatedness in addition to individual well-being.

Studies have also investigated the relationship between satisfaction with shopping experiences and well-being. Sirgy (2012) advocated that satisfaction with a shopping experience influenced several life domains, contributing to broader satisfaction with social, family, and financial life. Satisfaction across life domains thus characterizes one's overall life satisfaction. Carpenter and Moore (2006) stated that shopper satisfaction with a shopping experience was likely to vary by store type. Different stores offer varied shopping experiences that are likely to influence life satisfaction, as domains such as social, family, and leisure life are influenced by satisfaction with a store type. We argue that satisfaction with the experience of local coffee shops, which offer social space, can induce satisfaction across the various life domains of older people. If they are socially engaged, they feel a sense of belonging to the community, and thus their social well-being is enhanced.

H3. Elderly customers' satisfaction with coffee shops has a positive influence on their social well-being.

\subsubsection{The Mediating Effect of Customer Satisfaction on the Relationship between Social Interactions with Other Customers and Social Well-Being}

Some studies have found that positive CCls have a positive effect on satisfaction (Patterson, 1997; Bitzen, 1998). There is also evidence that interactions between the elderly in homecare facilities contribute to their satisfaction with the homecare services (Bergland and Kirkevold; 2008; Yeung et al., 2013). In addition, there is evidence suggesting that satisfaction with shopping, leisure, and tourism experiences have a positive effect on well-being and life satisfaction (Grzeskowiak et al., 2016; Sirgy, 2012). Few studies have examined the influence of customer satisfaction on the relationship between CCls and social well-being, but satisfaction with a store or a coffee shop, including satisfaction from interactions with other customers in the social environment, has been found to influence well-being because satisfaction with social interactions has a spillover effect on life domains such as happiness, confidence, and inclusiveness (Carpenter and Moore, 2006; Grzeskowiak et al., 2016; Sirgy, 2012). We thus propose the following hypothesis.

H4: The relationship between social interactions with other customers and social well-being is mediated by customer satisfaction; social interactions with other customers have a positive effect on customer satisfaction, which in turn has a positive effect on social wellbeing. 


\section{Methodology}

In the U.K., approximately $20 \%$ of the population is aged 60 and above, a proportion expected to rise to $24 \%$ by 2030 (Dickens et al., 2011). The well-being of older people is currently one of the main societal challenges in the U.K. and has economic and sociocultural implications.

\subsection{Sampling and Instrument}

The target population of this study comprised people in the U.K. aged 60 or above, as U.K. citizens are eligible for senior discounts and social programs after 60 years of age (Age UK, 2017). The sampling frame comprised respondents who visited a coffee shop more than once a year. We conducted structured interviews to collect data from 268 older people who visited independently owned or chain coffee shops from April 2016 to February 2017 in three locations (London, Oxford, and Plymouth) in the U.K. Convenience sampling (Miles and Huberman, 1994) was used to select 18 coffee shops and recruit the target population. Free coffee or tea was offered to the participants, and the interviews were self-administrated by one researcher to ensure nobody participated twice in the study. The questionnaire consisted of two sections. The first section included information such as the respondent's age, gender, and visiting frequency, and the second section comprised items cased in terms of the study constructs.

\subsection{Measures}

The measures were adapted from previous research to suit the purpose of this study. All manifest variables were measured on a 7-point Likert scale, ranging from "strongly disagree" to "strongly agree." The study examined three constructs, operationalized as follows. The main exogenous construct in this study was social interactions with customers (SIC), measured by four statements adopted from the scale developed by Walls (2013). The other exogenous latent variable-customer satisfaction (SATISF) - has appeared prominently in studies of service. The items used to measure customer satisfaction were adopted from Hoare and Butcher (2008). The outcome of interest in this study was social well-being (SWB), captured by four manifest indicators adopted from Wann and Pierce (2005) (see Figure 1 for more details). We selected these scales because they had high reliability and validity.

The Social Well-being with Life Scale was used to measure life satisfaction based on five items ("In most ways my life is close to my ideal," "The conditions of my life are excellent," "I am satisfied with my life," "So far I have gotten the important things I want in my life," and "If I could live my life over, I would change almost nothing") (Diener et al., 1985; Wann and Pierce, 2005). Wann and Pierce's study (2005) was based on data collected from 155 university students. We piloted our research instrument with a sample of older people before the main fieldwork commenced. After piloting the questionnaire, one of the five items ("If I could live my life over, I would change almost nothing") was excluded from the measurement because it was deemed to be emotionally sensitive and upsetting for the elderly sample in this study. All of the items used a 7point Likert scale, where 1 = "strongly disagree" and 7 = "strongly agree." As our study focused on the elderly population, we used a control variable related to age (AGE), whose measurement is depicted in Table 1. 


\subsection{Data Analysis}

The posited relationships in the conceptual model were tested in two steps. First, we used confirmatory factor analysis to assess the viability of the three constructs of interest. Second, we used a structural equation model (SEM) to test the relationships between latent variables (Figure 1). As some of the measures did not meet normality assumptions, we used maximum likelihood estimation to alleviate the effects of non-normality in the data (Anderson and Gerbing, 1988; Bentler, 1983). Confirmatory factor analysis and SEM were conducted using Stata 15 statistical software. In addition, we reran the SEM with bootstrapped standard errors to examine the mediating effect using Amos software. We also conducted a robustness check with partial least squares (PLS) modeling using Smart PLS software.

\section{See appendix for: Figure 1}

\section{Findings and Discussion}

\subsection{Descriptive Statistics}

The respondent profile indicated that approximately $60 \%$ of the respondents were male $(N=$ 178) (see Table 1). Customers in the sample were quite evenly distributed across two age brackets (60-69 and 70-79), and these groups accounted for more than $40 \%$ of the respondents each. As Table 1 shows, about $42 \%$ of the respondents visited coffee shops at least twice a week. Only $3 \%$ were first-time visitors. Among the three constructs, customer satisfaction had the highest mean (5.93), while social well-being had the highest standard deviation (1.28) (Table 1).

\section{See appendix for: Table 1}

\subsection{Measurement Model}

We conducted several analyses to evaluate the reliability and validity of the constructs. First, we calculated Cronbach's alpha to assess the scale reliability of each construct. The findings indicated that all three constructs exceeded the .70 threshold value for high internal consistency proposed by Nunnally (1978). Specifically, SIC, SATISF, and SWB had alpha values of $0.823,0.913$, and 0.913 , respectively (Table 2). We also used a composite reliability measure that was analogous to Cronbach's alpha but yielded less biased estimates (Fornell and Larcker, 1981). Composite reliability was computed using the relicoef routine in Stata 15. As Table 2 shows, all of the latent variables exceeded the threshold value of .70 .

\section{See appendix for: Table 2}

We assessed the convergent and discriminant validity of the constructs. Convergent validity indicated that the manifest variables loaded highly on the constructs they were expected to measure (Anderson and Gerbing, 1988). A significant $t$ value (minimally significant at the 0.01 level) for each item demonstrated that a given construct had convergent validity. Convergent validity was also 
indicated by the average variance extracted (AVE), which showed the proportion of variance explained relative to the unexplained variance (error variance). The AVE had a minimum acceptable threshold of 0.50 (Fornell and Larcker, 1981) and was computed using Stata 15's condisc routine.

The results in Table 2 reveal that all of the indicator loadings had significant $t$ values $(p \leq$ 0.001), indicating convergent validity. In addition, the AVE values of all of the constructs exceeded the threshold of 0.50 (i.e., SIC $=0.609$, SATISF $=0.666$, and SWB $=0.728$ ). These results confirmed that the measurement model exhibited convergent validity. We used several indices to evaluate how well our measurement model fit the data. Stata 15 reports two widely used incremental goodnessof-fit indices: the Tucker-Lewis Index (TLI) and Comparative Fit Index (CFI). A good fit is achieved when the TLI has a value of at least 0.95 . The TLI for our measurement model was 0.959 . The CFI was 0.967, superior to the suggested cutoff value of 0.95 . Based on the TLI and CFI values, we concluded that the posited measurement model fit the data very well.

The standardized root mean square residual (SRMR) value for the measurement model was 0.05, indicating a well-fitting model based on the suggested threshold value of 0.05 (Byrne, 1998). The root mean square error of approximation (RMSEA) value of 0.06 , the other residual measure, fell in the range of 0.05-0.08, as recommended by Hair, William, Babin, Anderson, and Tatham (2006).

\subsection{Structural Model}

The structural model was used to investigate the direct and indirect effects of SIC on SWB. We posited that SATISF would fully mediate the relationship between SIC and SWB. That is, after including the mediator (i.e., SATISF) in the model, we expected the relationship between SIC and SWB to no longer be significant. To test this claim, we first examined the direct effect of SIC on SWB in the absence of a mediator. The results indicated that SIC had a significant and positive effect on SWB, lending support to H1. This finding is consistent with previous studies in this area. For example, Kim et al. (2005) and Helliwell and Putman (2005) found that CCl facilitated social connectedness and thus had a positive effect on well-being. As Pettigrew (2007) and Pinquart and Sorensen (2001) found, elderly customers enjoy conversation with other customers, as it fulfills their companionship and emotional needs and helps them feel confident, loved, and understood. These effects contribute to the feeling of inclusiveness and belongingness that enhances the social well-being of older customers. Older customers visiting coffee shops in the U.K. exhibit a widespread preference to visit small privately owned and managed coffee shops, where they feel at ease with the straightforward setting and appreciate the more personal approach they take toward their customers, which addresses the emotional needs of the elderly. Our findings also support McColl-Kennedy et al. (2017), who found that elderly patients' interactions with their peers contributed to their well-being.

Second, we evaluated the fit indices of the structural model that included the three constructs: SIC, SATISF, and SWB. The findings in Table 3 show that the posited structural model achieved a good fit (CFI $=0.968, \mathrm{TLI}=0.960, \mathrm{RMSEA}=0.060, \mathrm{SRMR}=0.049)$. We then investigated whether the hypothesized paths were in the expected directions and whether they were significant at the 0.05 level. The first path tested the prediction that SIC would be positively related to SWB after controlling for AGE. Table 3 shows that the standardized coefficient was positive but not significant $(0.166, p>0.05)$, suggesting that we should test for full mediation in $\mathrm{H} 4$. In addition, AGE had a significant positive effect on SWB $(0.147, p \leq 0.01)$. 


\section{See appendix for: Figure 2}

The findings reveal that AGE was negatively related to SATISF $(-.202, p \leq 0.05)$, indicating that the older customers were less satisfied with the coffee shops' services. They imply that although the respondents received similar services, respondents of different ages might have had diverse expectations that affected their satisfaction. The younger respondents, mostly baby boomers, were more active and socially engaged and had more positive interactions with café employees and other customers, which in turn led to more satisfying consumption experiences. These findings are similar to those of a leisure experience study conducted by Patterson and Pegg (2009:267), who concluded that a "one size fits all" approach did not work in the seniors market because the baby boomer generation differed from previous generations of elderly consumers in their lifestyle patterns and consumption habits. Our subsequent analysis investigated the relationship between SIC and SATISF. The results indicate that SIC had a positive significant relationship with SATSIF $(0.222, p \leq 0.001)$ after controlling for AGE, consistent with the predictions of $\mathrm{H} 2$.

These findings show that elderly customers' interactions with other customers had a direct effect on both customer satisfaction and social well-being. The findings are in line with those of Tomazelli et al. (2017), Huang and Hsu (2010), Wei et al. (2017), and Wu (2007), who found that face-to-face communication and positive interactions between customers led to greater satisfaction. Such is the case for elderly customers who seek inclusiveness and a sense of belonging to the community in their interactions with other customers. These findings suggest that small hospitality organizations should assess the social factors that affect the social interactions of elderly customers with other customers, such as the opportunity to linger and socialize, feelings of ownership, the ability to territorialize, trust, respect, and support.

H3 postulates that SATISF is positively related to SWB. Table 3 shows that SATISF had a positive and significant influence on SWB $(0.116, p \leq 0.001)$. This indicates that satisfied customers are more likely to possess higher levels of social well-being, thus supporting H3. The result is also in line with the findings of Uysal et al. (2016), who suggested that leisure and tourism activities such as walking, travelling, and making art contributed to individual well-being. Our study also demonstrates that the hospitality industry, particularly coffee shops with their distinct characteristics (in terms of internal design), can offer a social space that leads to satisfaction with services and products while at the same time fulfilling the emotional needs of older customers. By offering newspapers, magazines, weekly meetings, and reading sessions, along with a nostalgic shop design, coffee shops can design an enjoyable consumption experience that facilitates social inclusiveness, confidence, relationship building, and well-being.

H4 predicts that SATISF fully mediates the relationship between SIC and SWB. As noted previously, full mediation occurred when the direct effect of the exogenous construct (i.e., SIC) on the endogenous construct (i.e., SWB) was insignificant after the addition of a mediator (Baron and Kenny, 1986). After including SATISF as a mediator, the direct effect of SIC on SWB was insignificant (see Table 3), so the full mediation model could be tested. The results show that SIC had a significant indirect effect on SWB through SATISF $(0.070, p \leq 0.05)$, confirming the presence of full mediation. 
Hence, the posited fully mediated relationship in $\mathrm{H} 4$ was confirmed, and thus our last hypothesis received empirical support.

The mediating effect of customer satisfaction on the relationship between social interactions with other customers and social well-being constitutes one of the key contributions of this study. More specifically, we found that social interactions with other customers had both direct (in the absence of customer satisfaction) and indirect effects on the social well-being of elderly customers in small hospitality business settings. Our findings also reveal that interactions during service encounters with other customers provided a feeling of inclusiveness among the older customers via customer satisfaction. Customer satisfaction thus appeared to be central to channeling the spill-over effects of social interactions to increase social well-being. Hospitality organizations should therefore improve satisfaction before, during, and after consumption to combine the experience of consumption with joy, happiness, and life satisfaction.

\section{See appendix for: Table 3}

At first glance, the coefficient of determination for the relationship between SIC and SAT may seem low (R2=.07). However, Srivastava and Kaul (2014) investigated the relationship between social interaction and satisfaction, and the path coefficient was not only lower but also negative $(-0.15)$. In the present study, the path coefficient was 0.22 in the direct model (i.e., for $\mathrm{H} 1$ ) and 0.18 in the mediated model.

Our results can be compared with those of other studies that have examined the determinants of well-being. McAuley et al. (2000) reported that social support captured $12.7 \%$ of the variance in subjective well-being. Rousseau and Vallerand (2008) found that obsessive passion was negatively related to subjective well-being $(-0.15)$. In hospitality management, human interaction measured by four dimensions had a weak and insignificant relationship with self-concept (0.06, n.s.) (Walls, 2013). Thus, we concluded that the path coefficients or coefficients of determination in our study were either on par with or stronger than those of past studies.

\subsection{Robustness Analysis}

The results of the first robustness check with Amos show that SIC did not have a significant effect on SWB, consistent with the main findings (see Table 4). Likewise, SIC was significantly related to CS $(0.265, p \leq 0.001)$, while CS had a significant effect on SWB $(\beta=.196, p \leq 0.001)$. A bootstrapping test revealed that CS mediated the relationship between SIC and SWB because the $95 \% \mathrm{Cl}$ did not contain zero.

\section{See appendix for: Table 4}

The robustness analysis indicated that the PLS findings largely mirrored those of our main analysis, where the relationship between SIC and SWB was fully mediated by CS. That is, according to the PLS-SEM results, the relationship between SIC and SWB was not significant (see Table 5). SIC had a significant effect on CS $(0.254, p \leq 0.001)$ ). , while CS was significantly related to SWB $(0.185, p$ 
$\leq 0.01)$. We checked both the total indirect effect and specific direct effect of CS on the link between SIC and SWB using PLS-SEM. The results reveal that CS mediated the relationship between CS and $\operatorname{SWB}(\beta=.047, p<.05)$.

\section{See appendix for: Table 5}

\section{Conclusions and Implications}

According to the United Nations World Population Prospects report (2017), the over-60 population is growing faster than all other age groups, and the number of people aged 60 or over is projected to more than double by 2050, rising from 962 million to 2.1 billion and reaching 3.1 billion by 2100 . Determining how to ensure the elderly stay socially connected and live an active life to prevent loneliness and isolation and enhance their social well-being has become a global challenge. In the U.K., research has revealed that one in eight people aged 65+ feel cut off from society (Davidson and Rossall, 2015), and according to the latest figures there are 1.4 million people in this age group (Age UK, 2018). The hospitality and tourism industry and, to a wider extent, the service industries are well positioned to play an influential facilitating role in addressing this global challenge, as demonstrated by some recent tourism studies (Kim et al., 2015; Uysal et al., 2016).

This study makes several timely and progressive contributions to the hospitality management literature by shedding light on how social interactions between older consumers and other customers influence the satisfaction and social well-being of the former. First, it is one of the few studies to examine the effect of $\mathrm{CCls}$ on customer satisfaction. Marketing and hospitality researchers have investigated customers' interactions with employees and their influence on customer satisfaction, but few studies have investigated the influence of $\mathrm{CCls}$ on satisfaction from the perspective of older customers. Positive social interactions with other customers in hospitality businesses can enhance the consumption experiences of older customers. This in turn improves their satisfaction, facilitates their inclusion in the wider community, and improves their social wellbeing.

Second, the study demonstrates the importance of commercial hospitality settings as a space for "experience creation for the elderly" that can help to alleviate social isolation. Thus, it offers an alternative avenue for hospitality research to further the understanding of the societal benefits of customer engagement in commercial hospitality settings. By undertaking an interdisciplinary study and exploiting constructs from multiple disciplines, including CCls, customer satisfaction (marketing and hospitality), and social well-being (sociology, psychology, and health care), this study highlights that the hospitality industry plays an important role in addressing a societal problem: the social connectedness and well-being of older people. Older customers' social well-being can be enhanced in their local, familiar environment through the social interaction platforms provided by local hospitality businesses. The findings of this study lend support to the argument that positive social interactions with other customers in hospitality settings strengthen feelings of inclusiveness and positive emotions among elderly customers via customer satisfaction. In a typical example, older customers suggest that they are more inclined to go to a place where they can have a "nice chat" with others, and they usually stay longer and pay more frequent visits as 
a result of the positive interactions and satisfying experience. Thus, considering how to improve the day-to-day well-being of the elderly in their local community is important for small business hospitality operations.

Third, the findings suggest that hospitality businesses should develop or update their training programs to increase employees' awareness of older customers' needs. We recommend that sector-based or industry-wide elderly-friendly training be introduced to encourage, engage, and empower the elderly to take initiatives to reduce their social isolation. A training manual may be developed for local hospitality managers and employees to help them facilitate their social interactions with older customers, and to create the required space and mechanisms to help them with other customer groups. In addition, hospitality businesses may co-create/co-produce socially conducive environments based on the input of elderly customers to help them enhance their satisfaction and social well-being.

Lastly, elderly-friendly regulations or recommended practices may be developed to inform design requirements. These may include specifications for the interiors and exteriors of hospitality businesses, which can be good places for elderly interaction and provide reasons to come and stay, comfort and safety, accessibility, and a warm welcome.

\section{Limitations and Recommendations for Further Research}

This study did not consider the effects of cultural differences and values on the relationships between social interactions, customer satisfaction, and social well-being, which may affect the robustness of the findings. Future research may investigate the influence of culture and subcultures on the interface between interactions, customer satisfaction, and social well-being and conduct comparative studies across different cultural settings. In addition, we did not consider how interactions and customer satisfaction could influence the loneliness of older customers, and future studies may examine these factors. Customer experience may be added to the proposed model as a moderator to enhance the contribution of the study. Furthermore, the results derived from this quantitative study show that the younger respondents, mostly baby boomers, appeared to be more satisfied than the older respondents, but the underlying reasons are not fully known. Future research may adopt a qualitative approach to investigate why such differences in opinion exist and how hospitality and tourism businesses can cater to the diverse needs of the rapidly growing seniors market. We hope this study spurs research interest in exploring older customers' perspectives at a global level.

\section{Acknowledgments}

The authors would like to acknowledge the financial support of the Hong Kong Polytechnic University (Grant No.: 1-ZVGY)

All of the authors contributed equally to this manuscript. 
Table 1

Descriptive statistics

\begin{tabular}{|c|c|c|c|}
\hline Variable & Frequencs & $\%$ & \\
\hline \multicolumn{4}{|l|}{ Gender } \\
\hline Male & 178 & 59.93 & $\bar{\Gamma}$ \\
\hline Female & 119 & 40.07 & $\overline{1}$ \\
\hline \multicolumn{4}{|l|}{ Age (years) } \\
\hline $60-69$ years & 138 & 46.31 & \\
\hline $70-79$ & 123 & 41.28 & 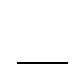 \\
\hline $80-89$ & 33 & 11.07 & 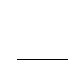 \\
\hline 90 and over & 4 & 1.34 & $\overline{.}$ \\
\hline \multicolumn{4}{|l|}{ Visiting frequency } \\
\hline More than 3 times a week & 52 & 17.22 & 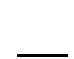 \\
\hline About 2 or 3 times a week & 78 & 25.83 & 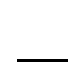 \\
\hline About once a week & 55 & 18.21 & 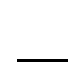 \\
\hline About 2 or 3 times a month & 51 & 16.89 & 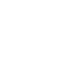 \\
\hline About once a month & 33 & 10.93 & 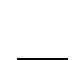 \\
\hline Less than 2-3 times a year & 20 & 6.62 & $\bar{L}$ \\
\hline Less than once a year & 3 & 0.99 & $\underline{-}$ \\
\hline \multirow[t]{2}{*}{ This is my first visit } & 10 & 3.31 & $\underline{-}$ \\
\hline & Mean & SD & 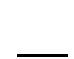 \\
\hline $\begin{array}{l}\text { Service Interaction with } \\
\text { Customers }\end{array}$ & 5.21 & 0.96 & - \\
\hline Customer Satisfaction & 5.93 & 0.89 & $\underline{.}$ \\
\hline Social Well-Being & 5.12 & 1.28 & $\underline{-}$ \\
\hline
\end{tabular}


Table 2

Measurement scale properties

\begin{tabular}{|c|c|c|c|c|c|}
\hline Indicator & $\begin{array}{c}\text { Standardized } \\
\text { Loadings }\end{array}$ & Error Variance & AVE & Alpha & $\mathrm{CR}$ \\
\hline$\overline{S I C}$ & & & 0.609 & 0.823 & 0.860 \\
\hline SIC1 & $0.772 *$ & 0.404 & & & \\
\hline $\mathrm{SIC} 2$ & $0.877^{*}$ & 0.231 & & & \\
\hline SIC3 & $0.857^{*}$ & 0.264 & & & \\
\hline SIC4 & $0.579 *$ & 0.664 & & & \\
\hline$\overline{S A T I S F}$ & & & 0.666 & 0.915 & 0.909 \\
\hline SATISF1 & $0.710^{*}$ & 0.495 & & & \\
\hline SATISF2 & $0.840^{*}$ & 0.295 & & & \\
\hline SATISF3 & $0.869^{*}$ & 0.245 & & & \\
\hline SATISF4 & $0.843 *$ & 0.291 & & & \\
\hline SATISF5 & $0.808^{*}$ & 0.348 & & & \\
\hline$\overline{S W B}$ & & & 0.728 & 0.913 & 0.914 \\
\hline SWB1 & $0.852^{*}$ & 0.274 & & & \\
\hline SWB2 & $0.819^{*}$ & 0.330 & & & \\
\hline SWB3 & $0.943^{*}$ & 0.112 & & & \\
\hline SWB4 & $0.793^{*}$ & 0.371 & & & \\
\hline
\end{tabular}


Figure 1

Posited conceptual model

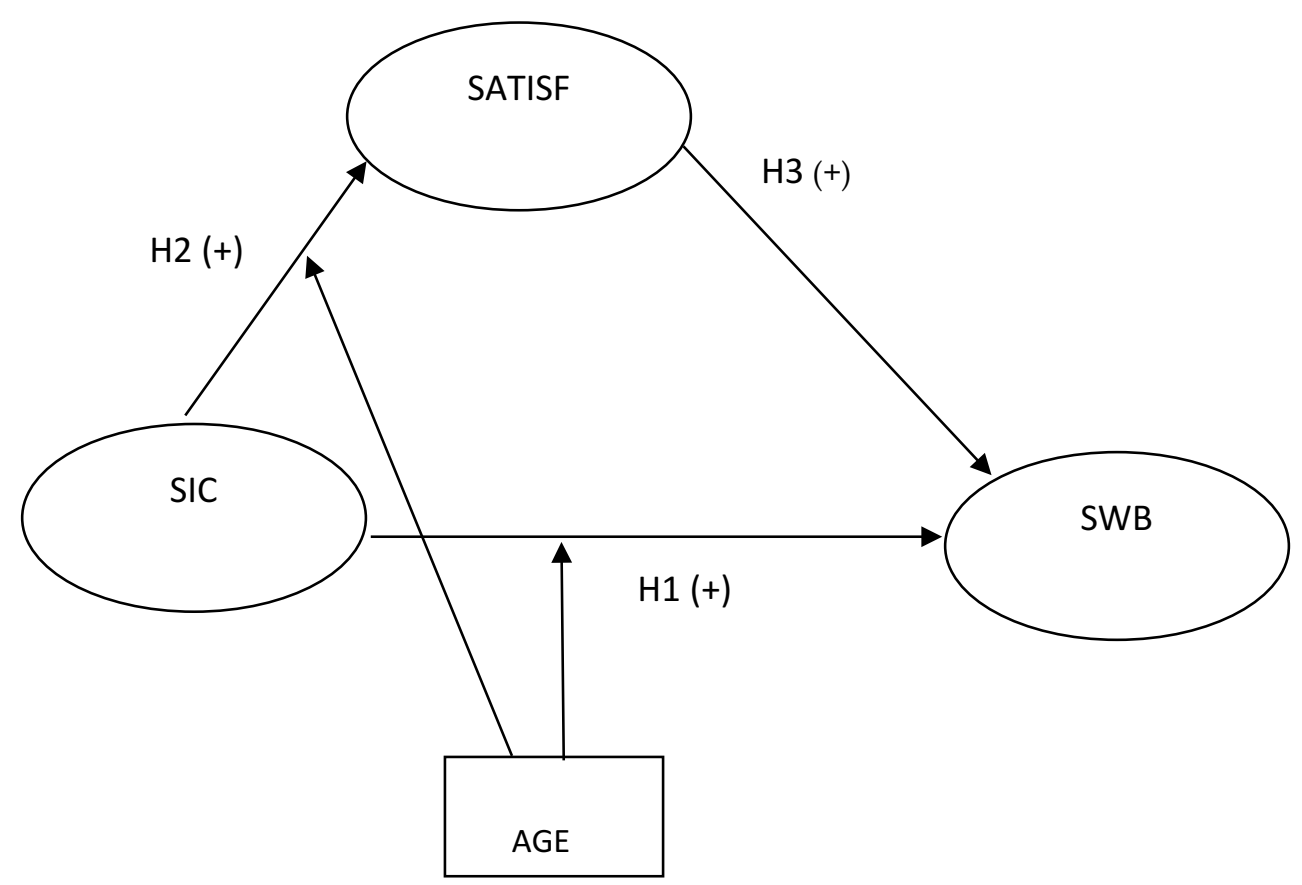

Notes: $\mathrm{SIC}=$ social interaction with customers; $\mathrm{SATISF}=$ customer satisfaction; $\mathrm{SWB}=$ social well-being. 
Figure 2

Path coefficients for the posited model

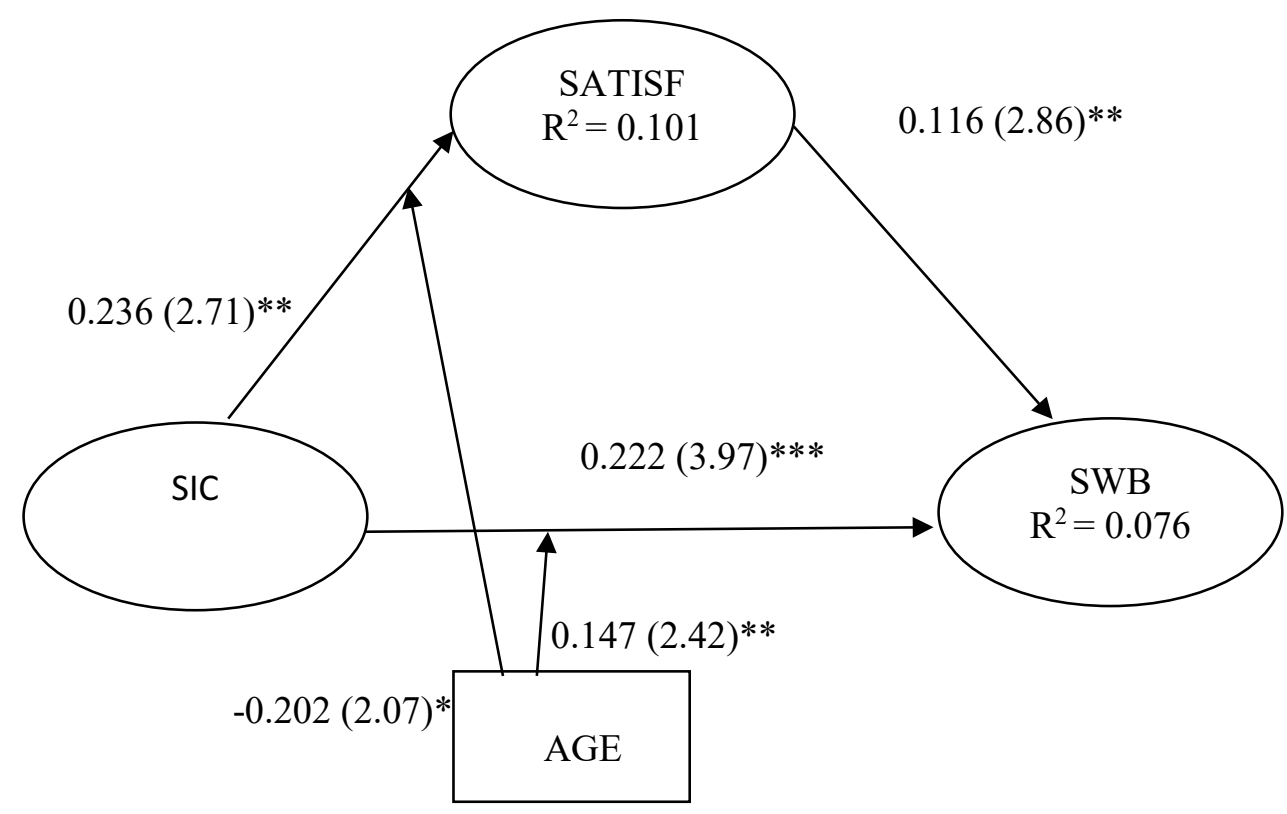

Notes: $\mathrm{T}$-values are shown in parenthesis; $\mathrm{SIC}=$ social interaction with customers; $\mathrm{SWB}=$ social well-being; $\mathrm{SATISF}=$ customer satisfaction. 
Table 3

Structural equation results and mediation analysis

\begin{tabular}{|c|c|c|}
\hline \multicolumn{3}{|l|}{ Measurement Model Fit } \\
\hline \multicolumn{3}{|l|}{$\chi^{2}=135.301(\mathrm{df} 62) p \leq 0.001$} \\
\hline \multicolumn{3}{|c|}{$\mathrm{CFI}=0.967 \mathrm{TLI}=0.959 \mathrm{RMSEA}=0.066 \mathrm{SRMR}=0.050$} \\
\hline \multicolumn{3}{|l|}{ Structural Model Fit } \\
\hline \multicolumn{3}{|l|}{$\chi^{2}=142.623(\mathrm{df} 72) p \leq 0.001$} \\
\hline \multicolumn{3}{|c|}{$\mathrm{CFI}=0.968 \mathrm{TLI}=0.960 \mathrm{RMSEA}=0.060 \mathrm{SRMR}=0.049$} \\
\hline Hypothesized Path & $\beta$ (t-value) & Supported \\
\hline H1: SIC $\rightarrow$ SWB & $0.166(1.86)$ & YES (based on $0.236(2.71)$ ) \\
\hline H2: SIC $\rightarrow$ SATISF & $0.222(3.97)^{* * *}$ & YES \\
\hline H3: SATISF $\rightarrow$ SWB & $0.319(2.87)^{* *}$ & YES \\
\hline H4: SIC $\rightarrow$ SATISF $\rightarrow$ SWB & $0.070(2.39)^{*}$ & YES \\
\hline
\end{tabular}

Notes: ${ }^{* * *} p \leq .001 ;{ }^{* *} p \leq .01 ;{ }^{*} p \leq .05 ; \mathrm{t}$-values are shown in parenthesis. 


\section{Table 4}

Robustness analysis with partial least structural squares equation modeling (PLS-SEM)

\begin{tabular}{|l|c|c|c|}
\hline Hypothesized Path & $\beta$ (t value) & & Supported \\
\hline H1. SIC $\rightarrow$ SWB & .089 & & NO \\
\hline H2. SIC $\rightarrow$ SATISF & $.265^{* * *}$ & & YES \\
\hline H3. SATISF (CS) $\rightarrow$ SWB & $.196^{* * *}$ & & YES \\
\hline & & & \\
\hline Mediating role of SATISF & B (SE boot $^{*}$ & $95 \%$ CI & \\
\hline H4. SIC $\rightarrow$ SATISF $\rightarrow$ SWB & $.047(0.022)$ & $0.013,0.099$ & YES \\
\hline
\end{tabular}




\section{Table 5}

Robustness analysis with partial least structural squares equation modeling (PLS-SEM)

\begin{tabular}{|l|c|c|}
\hline Hypothesized Path & \multicolumn{2}{|c|}{ Supported } \\
\cline { 2 - 3 } & $0.089(1.426)$ & \\
\hline H1. SIC $\rightarrow$ SWB & $0.254(3.724)^{* * *}$ & NO \\
\hline H2. SIC $\rightarrow$ SATISF & $0.185(2.88)^{* *}$ & YES \\
\hline H3. SATISF $\rightarrow$ SWB & & YES \\
\hline & $\beta(t-v a l u e)$ & \\
\hline Mediating role of SATISF & $0.047(2.152)^{*}$ & YES \\
\hline H4. SIC $\rightarrow$ SATISF $\rightarrow$ SWB & & \\
\hline
\end{tabular}




\section{References}

Abrams, M., 1973. Subjective social indicators. Social Trends. 4, 35-50.

Age UK, 2017. https://www.ageuk.org.uk/information-advice/money-legal/benefitsentitlements/free-bus-pass-and-transport-concessions/ [Accessed on 27 December 2017].

Age UK, 2018. Later Life in the United Kingdom. Age UK Report. April 2018. https://www.ageuk.org.uk/globalassets/age-uk/documents/reports-andpublications/later life uk factsheet.pdf [Accessed on 17 June 2018].

Aller, L. J., Van Ess Coeling, H., 1995. Quality of life: Its meaning to the long-term care resident. Journal of Gerontological Nursing. 21 (2), 20-25.

Anderson, J., Gerbing, D., 1988. Structural equation modeling in practice: A review and recommended two-step approach. Psychological Bulletin. 103 (3), 411-423.

Ayis, S., Gooberman-Hill, R., Ebrahim, S., 2003. Long-standing and limiting illness in older people: Associations with chronic diseases, psychological and environmental factors. Age and Ageing. 32 (3), 265-272.

Backstrom, K., Johansson, U., 2006. Creating and consuming experience in retail store environments: Comparing retailer and consumer perspectives. Journal of Retailing and Consumer Services. 13, 417-430.

Baron, R., Kenny, D., 1986. The moderator-mediator variable distinction in social psychological research: Conceptual, strategic, and statistical considerations. Journal of Personality and Social Psychology. 51 (6), 1173-1182.

Bentler, P. M., 1983. Some contributions to efficient statistics in structural models: Specification and estimation of moment structures. Psychometrika. 48 (4), 493-517.

Bergland, Å., Kirkevold, M., 2008. The significance of peer relationships to thriving in nursing homes. Journal of Clinical Nursing. 17 (10), 1295-1302.

Bitner, M. J., 1992. Servicescapes: The impact of physical surroundings on customers and employees. Journal of Marketing. 56, 57-71.

Bitner, M. J., Booms, B. H., Mohr, L. A., 1994. Critical service encounters: The employee's view. Journal of Marketing. 58, 95-106.

Bitzen, J., 1998. Emotional bondedness and subjective well-being. Journal of Gerontological Nursing. 24, 8-15.

Brady, M. K., Cronin, J., 2001. Some new thoughts on conceptualizing perceived service quality: A hierarchical approach. Journal of Marketing. 65, 34-49. 
Breen, H., 2009. Senior citizen bingo players in Australian registered and licensed clubs: A case study at Tweet Heads, New South Wales. Journal of Travel and Tourism Marketing. 26 (4), 383-394.

Byrne, B., 1998. Structural equation modeling with LISREL, PRELIS, and SIMPLIS: Basic concepts, applications, and programming. Mahwah, NJ: Erlbaum.

Carpenter, J. M., Moore, M., 2006. Consumer demographics, store attributes, and retail format choice in the US grocery market. International Journal of Retail \& Distribution Management. 34 (6), 434-452.

Carpentier, N., 2015. Differentiating between access, interaction and participation. Conjunctions. Transdisciplinary Journal of Cultural Participation. 2 (2), 7-28.

Cheng, S. T., Lee, C. K. L., Chow, P. K., 2010. Social support and psychological well-being of nursing home residents in Hong Kong. International Psychogeriatrics. 22 (7), 11851190 .

Choi, B. J., Kim, H. S., 2013. The impact of outcome quality, interaction quality, and peer-topeer quality on customer satisfaction with a hospital service. Managing Service Quality: An International Journal. 23 (3), 188-204.

Davidson, S., Rossall, P., 2015. Age UK Loneliness Evidence Review Report, Age UK, July 2015. https://www.ageuk.org.uk/globalassets/age-uk/documents/reports-andpublications/reports-and-briefings/health-wellbeing/rb june15 lonelines_in_later_life_evidence_review.pdf. [Accessed on 17 June 2018].

Deci, E. L., Ryan, R. M., 2008. Self-determination theory: A macrotheory of human motivation, development and health. Canadian Psychology. 49 (3), 182-185.

Dickens, A. P., Richards, S. H., Hawton, A., Taylor, R. S., Greaves, C. J., Green, C., Edwards, R., Campbess, J. L., 2011. An evaluation of the effectiveness of a community mentoring service for socially isolated older people: a controlled trial. BMC Public Health. 11, 218.

Diener, E., Emmons, R. A., Larsen, R. J., \& Griffin, S., 1985. The Satisfaction with Life Scale. Journal of Personality Assessment. 49, 71-75.

Diener, E., Lucas, R. E., Smith, O., 2002. Subjective well-being. Handbook of Positive Psychology. 16 (2), 63-73.

Diener, E., Oishi, S., Lucas, R. E., 2015. National accounts of subjective well-being. American Psychologist. 70 (3), 234.

Diener, E., Seligman, M. E., 2002. Very happy people. Psychological Science. 13 (1), 81-84.

Diener, E., Seligman, M. E., 2004. Beyond money: Toward an economy of well-being. American Psychological Society. 5 (1), 1-31. 
Diener, E., Suh, E., Lucas, R., Smith, H., 1999. Subjective well-being: Three decades of progress. Psychological Bulletin. 125 (2), 276-302.

Duerden, M. D., Ward, P. J., Freeman, P. A., 2015. Conceptualizing structured experiences. Journal of Leisure Research. 47 (5), 601-620.

Dunbar, R., 2016. Friends on tap: The role of pubs at the heart of the community: A report for CAMRA. Oxford: Department of Experimental Psychology, University of Oxford.

Edgar, F., Geare, A., Saunders, D., Beacker, M., Faanunu, I., 2017. A transformative service research agenda: A study of workers' well-being. The Service Industries Journal. 37 (1), 84-104.

Eger, R. J., Maridal, J. H., 2015. A statistical meta-analysis of the wellbeing literature. International Journal of Wellbeing. 5 (2), 123-157.

Ekpo, A., Riley, B., Thomas, K. D., Yvaire, Z., Henderson, G., Geraldine, R., Munoz, I., 2015. As worlds collide: The role of marketing management in customer-to-customer interactions. Journal of Business Research. 68 (1), 119-126.

Ellis, G. D., Freeman, P. A., Jamal, T., Jiang, J., 2017. A theory of structured experience. Annals of Leisure Research. 1-22. DOI: 10.1080/11745398.2017.1312468

Esbjerg, L., Jensen, B. B., Bech-Larsen, T., de Barcellos, M. D., Boztug, Y., Grunert, K. G., 2012. An integrative conceptual framework for analysing customer satisfaction with shopping trip experiences in grocery retailing. Journal of Retailing and Consumer Services. 19 (4), 445-456.

Fornell, C., Larcker, D., 1981. Evaluating structural equation models with unobservable variables and measurement error. Journal of Marketing Research. 18 (1), 39-50.

Gerrard, P., Cunningham, B., 2001. Bank service quality: A comparison between a publicly quoted bank and government bank in Singapore. Journal of Financial Services Marketing. 6 (1), 50-66.

Grönroos, C., 1982. Strategic management and marketing in the service sector. Swedish School of Economics and Business Administration, Helsingfors.

Grönroos, C., 1984. A service quality model and its marketing implications. European Journal of Marketing. 8 (4), 36-44.

Grzeskowiak, S., Sirgy, J., Foscht, T., Swoboda, B., 2016. Linking retailing experiences with life satisfaction. International Journal of Retail \& Distribution Management. 44 (2), 124-138.

Gutheil, I., 1991. Intimacy in nursing home friendships. Journal of Gerontological Social Work. 17 (1/2), 59-73.

Hair, J., William, C., Babin, B., Anderson, R., Tatham, R., 2006. Multivariate data analysis. Upper Saddle River, NJ: Pearson University Press. 
Helliwell, J. F., Putnam R. D., 2005. The social context of well-being. In: Huppert, F., Beylis, B. K., Keverne, B., (Eds.). The science of well-being. Oxford University Press, Oxford.

Hoare, R., Butcher, K., 2008. Do Chinese cultural values affect customer satisfaction/ loyalty? International Journal of Contemporary Hospitality Management. 20 (2), 156171.

Huang, J., Hsu, C. H., 2010. The impact of customer-to-customer interaction on cruise experience and vacation satisfaction. Journal of Travel Research. 49 (1), 79-92.

Huddleston, P., Ford, I., Mahoney, M. Y., 1990. The relationship between importance of retail store attributes and lifestyle of mature female consumers. International Journal of Consumer Studies. 14 (1), 71-85.

Hutchinson, S., Kleiber, D. A., 2005. Gifts of the ordinary: Casual leisure's contributions to health and well-being. World Leisure, 47(3), 2-16.

Jamel, A., Naser, K., 2002. Customer satisfaction and retail banking: An assessment of some of the key antecedents of customer satisfaction in retail banking. International Journal of Bank Marketing. 20 (4/5), 146-160.

Jopling, K., 2015. Promising approaches to reducing loneliness and isolation in later life. London: Age UK.

Kahneman, D., Diener, E., Schwarz, N., 1999. Well-being: Foundations of hedonic psychology. New York: Russell Sage Foundation.

Keyes, C. L. M., 1998. Social well-being. Social Psychology Quarterly. 61 (2), 121-140.

Keyes, C. L., Shmotkin, D., Ryff, C. D., 2002. Optimizing well-being: The empirical encounter of two traditions. Journal of Personality and Social Psychology. 82 (6), 1007.

Kim, H. S.,_Choi, B., 2016. The effects of three customer-to-customer interaction quality types on customer experience quality and citizenship behavior in mass service settings. Journal of Services Marketing. 30 (4), 384-397.

Kim, Y. K., Kang, J., Kim, M., 2005. The relationships among family and social interaction, loneliness, mall shopping motivation, and mall spending of older consumers.

Psychology \& Marketing. 22 (12), 995-1015.

Kim, Y., Kim, E., Kang, J., 2003. Teens' mall shopping motivations: Functions of loneliness and media usage. Family and Consumer Sciences Research Journal. 32 (2), 140-167.

Kim, H., Woo E., Uysal, M., 2015. Tourism experience and quality of life among elderly tourists. Tourism Management. 46 (February), 465-476.

Kuykendall, L., Tay, L., Ng, V., 2015. Leisure engagement and subjective well-being: A meta-analysis. Psychology Bulletin. 141 (2), 364. 
Lamers, S. M. A., Westerhof, G. J., Bohlmeijer, E. T., Klooster, P. M., Keyes, C. L. M., 2011. Evaluating the psychometric properties of the mental health continuum-short form (MHC-SF). Journal of Clinical Psychology. 67 (1), 99-110.

Larson, J. S., 1993. The measurement of social well-being. Social Indicators Research. 28 (3), 285-296.

Lauder, W., Mummery, K., Jones, M., Caperchione, C., 2006. A comparison of health behaviours in lonely and non-lonely populations. Psychology, Health \& Medicine. 11 (2), 233-245.

Lee, R. M., Keough, K. A., Sexton, J. D., 2002. Social connectedness, social appraisal, and perceived stress in college women and men. Journal of Counseling \& Development. 80 (3), 355-361.

Lee, R. M., Robbins, S. B., 2000. Understanding social connectedness in college women and men. Journal of Counseling \& Development. 78 (4), 484-491.

Lehtinen, U., Lehtinen, J. R., 1982. Service quality: A study of quality dimensions. Service Management Institute.

Lemke, F., Clark, M., Wilsom, J., 2011. Customer experience quality: An exploration in business and consumer contexts using repertory grid technique. Journal of the Academy of Marketing Science. 39 (December), 846-869.

Levasseur, M., Desrosiers, J., Noreau, L., 2004. Is social participation associated with quality of life of older adults with physical disabilities? Disability and Rehabilitation. 26 (20), 1206-1213.

Linkins, M., Niemiec, M. R., Gillham, J., Mayerson, D., 2015. Through the lens of strength: A framework for educating the heart. Journal of Positive Psychology. 10(1), 64-68.

Lugosi, P., Robinson, N. S. R., Golubosvska, M., Foley, L., 2016. The hospitality consumption experiences of parents and carers with children: A qualitative study of foodservice settings. International Journal of Hospitality Management. 54 (April), 8494.

Lugosi, P., 2009. The production of hospitable space: Commercial propositions and consumer co-creation in a bar operation. Space and Culture. 12 (4), 396-411.

Mattiasson, A. C., Andersson, L., 1997. Quality of nursing home care assessed by competent nursing home patients. Journal of Advanced Nursing. 26 (6), 1117-1124.

McAuley, E., Blissmer, B., Marquez, D. X., Jerome, G. J., Kramer, A. F., Katula, J., 2000. Social relations, physical activity, and well-being in older adults. Preventive Medicine. 31 (5), 608-617.

McCall, C., 1975. Quality of life. Social Indicators Research. 2 (2), 229-248. 
McColl-Kennedy, J. R., Cheung, L., Ferrier, E., 2015. Co-creating service experience practices. Journal of Service Management. 26 (2), 249-275.

McColl-Kennedy, J. R., Danaher, T. S., Gallan, A. S., Orsingher, C., Lervik-Olsen, L., Verma, R., 2017. How do you feel today? Managing patient emotions during health care experiences to enhance well-being. Journal of Business Research. 79, 247-259.

Mead, G. H., 1934. Mind, self and society: From the standpoint of a social behaviouralist. Ed. Charles W. Morris, Chicago: University of Chicago Press.

Miles, M. B., Huberman, A. M., 1994. Qualitative data analysis: An expanded sourcebook (2nd ed.), Thousand Oaks, CA: Sage.

Moura, P., Amorim, M., 2017. A typology of customer-to-customer interaction and its implications for excellence in service provision. Total Quality Management and Business Excellence. 28, 1183-1193.

Neal, J. D., Uysal M., Sirgy M. J., 2007. The effect of tourism services on traveller's quality of life. Journal of Travel Research. 46 (November), 154-163.

Netuveli, G., Wiggins, R. D., Hildon, Z., Montgomery, S. M., Blane, D., 2005. Functional limitation in long standing illness and quality of life: Evidence from a national survey. British Medical Journal. 331, 1382-1383.

Nicholls, R., 2011. Customer-to-customer interaction: a cross-cultural perspective. International Journal of Contemporary Hospitality Management. 23(2), 15-16.

Nunnally, J., 1978. Psychometric theory. New York: McGraw-Hill.

Oliver, R. L., DeSarbo, W. S., 1988. Response determinants in satisfaction judgments. Journal of Consumer Research. 14, 495-507.

Oliver, R. L., 1993. A conceptual model of service quality and service satisfaction; Compatible goals, different concepts. Advances in Services Marketing and Management. 2, 65-68.

Oliver, R. L., 1997. Satisfaction: A behavioral perspective on the consumer. Boston, MA: McGraw-Hill.

Oliver, R. L., 2006. Customer satisfaction research. The Handbook of Marketing Research: Uses, Misuses, and Future Advances, Vol. 1. Thousand Oaks, CA: Sage.

Orsega-Smith, E. M., Payne, L. L., Mowen, A. J., Ho, C.-H., Godbey, G. C., 2007. The role of social support and self-efficacy in shaping the leisure time physical activity of older adults. Journal of Leisure Research. 39 (4), 705-727.

Palys, T. S., Little, B. R., 1983. Perceived life satisfaction and the organization of personal project systems. Journal of Personality and Social Psychology. 44 (6), 1221.

Patterson, K., 1997. Delighted clients are loyal clients. Rough Notes. 140 (3), 221-234. 
Patterson, I., Pegg, S., 2009. Marketing the leisure experience to baby boomers and older tourists. Journal of Hospitality Marketing and Management. 18 (2-3), 254-272.

Patterson, P.G., Spreng, R.A., 1997. Modelling the relationship between perceived value, satisfaction and repurchase intentions in a business-to-business, services context: An empirical examination. The International Journal of Service Industry Management, 8 (5), 415-432.

Pettigrew, S., 2007. Reducing the experience of loneliness among older consumers. Journal of Research for Consumers. 12, 1-4.

Pinquart, M., Sörensen, S., 2001. Influences on loneliness in older adults: A meta-analysis. Basic \& Applied Social Psychology. 23 (4), 245-266.

Prince-Paul, M., 2008. Relationships among communicative acts, social well-being, and spiritual well-being on the quality of life at the end of life in patients with cancer enrolled in hospice. Journal of Palliative Medicine. 11 (1), 20-25.

Quinlan, M., D, Swain, N., Cameron, C. Dianne A. Vella-Brodrick, D. A., (2015). How 'other people matter' in a classroom-based strengths intervention: Exploring interpersonal strategies and classroom outcomes. Journal of Positive Psychology. May, 77-89.

Rook, K. S., 1984. The negative side of social interaction: Impact on psychological wellbeing. Journal of Personality and Social Psychology. 46 (5), 1097-1108.

Rousseau, F. L., Vallerand, R. J., 2008. An examination of the relationship between passion and subjective well-being in older adults. The International Journal of Aging and Human Development. 66 (3), 195-211.

Sacco, M., Ismail, M., 2014. Social belongingness satisfaction as a function of interaction medium: Face-to-face interactions facilitate greater social belonging and interaction enjoyment compared to instant messaging, Computers in Human Behavior. 36 (July), 359-364.

Seligman, M. E., Csikszentmihalyi, M., 2000. Positive psychology: An introduction. American Psychologist. 55 (1), 5-14.

Seligman, M. E., 2002. Authentic happiness: Using the new positive psychology to realize your potential for lasting fulfillment. New York: The Free Press.

Shin, D., Johnson, D., 1978. Avowed happiness as an overall assessment of the quality of life. Social Indicators Research: An International and Interdisciplinary Journal for Quality-of-Life Measurement. 5 (1), 475-492.

Sirgy, M. J., 2012. The psychology of quality of life: Hedonic well-being, life satisfaction, and eudaimonia, 2nd ed. New York, NY: Springer. 
Song, H., Altinay, L., Wang, X. L. and Sun, T., 2018. The influence of social interactions on elderly consumers' customer experience and loneliness. International Journal of Contemporary Hospitality Management. https://doi.org/10.1108/IJCHM-07-2017-0442

Srivastava, M., Kaul, D., 2014. Social interaction, convenience and customer satisfaction: The mediating effect of customer experience. Journal of Retailing and Consumer Services. 21, 1028-1037.

Stalker, G. J., 2008. Measuring diversity in daily social contact: The contribution of social context, work, and leisure on the opportunity for engagement. Social Indicator Research. 86 (2), 275-295.

Surprenant, C. F., Solomon, M. R., 1987. Predictability and personalization in the service encounter. Journal of Marketing. 51, 86-96.

Toepoel, V., 2013. Ageing, leisure, and social connectedness: How could leisure help reduce social isolation of older people? Social Indicators Research. 113 (1), 355-372.

Tomazelli, J., Broilo, P. L., Espartel, B. L., Basso, K., 2017. The effects of store environment elements on customer-to-customer interactions involving older shoppers. Journal of Services Marketing. 4(5), 339-250.

Tse, D. K., Wilton, P. C., 1988. Models of consumer satisfaction formation: An extension. Journal of Marketing Research. 25 (2), 86-97.

United Nations, Department of Economic and Social Affairs, Population Division, 2017. World Population Prospects: The 2017 Revision, Key Findings and Advance Tables. Working Paper No. ESA/P/WP/248.

Uysal, M., Sirgy, J. M., Eunju, W., Kim, H., 2016. Quality of life (QOL) and well-being research in tourism. Tourism Management. 53, 244-261.

Verhoef, P. C., Lenon, K. N., Parasuraman, A., Roggeveen, A., Tsiros, M., Schlesinger, L. A., 2009. Customer experience quality: Determinants, dynamics and management strategies. Journal of Retailing. 85 (1), 31-41.

Walls, R. A., 2013. A cross-sectional examination of hotel consumer experience and relative effects on consumer values. International Journal of Hospitality Management. 32, 179192.

Wann, D. L., Pierce, S., 2005. The relationship between sport team identification and social well-being: Additional evidence supporting team identification-social psychological health model. North American Journal of Psychology. 7 (1), 117-124.

Wei, W., Lu, Y., Miao, L., Cai, A. L., Wang, C., 2017. Customer-to-customer interactions (CCIs) at conferences: An identity approach. Tourism Management. 59, 154-170.

White, M. A., Waters, E. L., 2015. A case study of 'The Good School:' Examples of the use of Peterson's strengths-based approach with students. Journal of Positive Psychology. 69-76. 
Windle, K., Francis, J., Coomber, C., 2014. Preventing loneliness and social isolation: Interventions and outcomes. Social Care Institute for Excellence, Research Briefing. $39,1-16$.

Woodside, A. G., Sims, T. J., 1976. Retail sales transactions and customer 'Purchase Pal' effects on buying behaviour. Journal of Retailing. 52, 57-64.

Wu, H. C., 2007. The impact of customer-to-customer interaction and customer homogeneity on customer satisfaction in tourism service - The service encounter perspective. Tourism Management. 28, 1518-1528.

Yi, Y., 1990. A critical review of consumer satisfaction. Review of Marketing. 4 (1), 68-123.

Yeung, D. Y., Kwok, S. Y., Chung, A., 2013. Institutional peer support mediates the impact of physical declines on depressive symptoms of nursing home residents. Journal of Advanced Nursing. 69 (4), 875-885.

Yin, C., Poon, P., 2016. The impact of other groups members on tourists' travel experiences. International Journal of Contemporary Hospitality Management. 28 (3), 640-658.

Yoo, J., Arnold, T. J., Frankwick, L. G., 2012. Effects of positive customer-to-customer service interaction. Journal of Business Research. 65, 1313-1320.

Zaninotto, P., Falaschetti, E., Sacker. A., 2009. Age trajectories of quality of life among older adults: Results from the English longitudinal study of ageing. Quality of Life Research. 18, 1301-1309.

Zhou, L., Wu, M., Wall, G., Pearce, L. P., 2018. Seniors' seasonal movements for health enhancement. The Service Industries Journal. 38 (1-2), 27-47. 